\title{
Impacts of climate change on the potential forest productivity based on a climate-driven biophysical model in northeastern China
}

\author{
Wen-Qiang $\mathrm{Gao}^{1} \cdot$ Xiang-Dong Lei $^{1} \cdot$ Li-Yong Fu ${ }^{1}$
}

Received: 21 November 2018/Accepted: 16 January 2019/Published online: 24 June 2019

(C) The Author(s) 2019

\begin{abstract}
Climate warming is expected to influence forest growth, composition and distribution. However, accurately estimating and predicting forest biomass, potential productivity or forest growth is still a challenge for forest managers dealing with land-use at the stand to regional levels. In the present study, we predicted the potential productivity (PP) of forest under current and future climate scenarios (RCP2.6, RCP4.5, RCP6.0 and RCP8.5) in Jilin province, northeastern China by using Paterson's Climate Vegetation and Productivity (CVP) index model. The PP was validated by comparing it with the mean and maximum net primary production calculated from light energy utilization (GLM_PEM). Our results indicated that using the CVP index model is partially valid for predicting the potential forest productivity in northeastern China. PP exhibited obvious spatial heterogeneity varying from 4.6 to $8.9 \mathrm{~m}^{3} \mathrm{ha}^{-1}$ year $^{-1}$ with an increasing tendency from northwest to southeast driven by the precipitation across the region. The number of vegetation-active months, precipitation and insolation coefficient were identified as the
\end{abstract}

Project funding: This work was supported by the Forestry Public Welfare Scientific Research Project (No. 201504303) and the Fundamental Research Funds for the Central Non-profit Research Institute of CAF (CAFYBB2018SY022).

The online version is available at http://www.springerlink.com.

Corresponding editor: Chai Ruihai.

Xiang-Dong Lei

xdlei@ifrit.ac.cn

1 Institute of Forest Resource Information Techniques, Chinese Academy of Forestry, Key Laboratory of Forest Management and Growth Modelling, State Forestry and Grassland Administration, Beijing 100091, People's Republic of China primary factors affecting PP, but no significant relationship was found for warmest temperature or temperature fluctuation. Under future climate scenarios, PP across the Jilin Province is expected to increase from $1.38 \%$ (RCP2.6 in 2050 ) to $15.30 \%$ (RCP8.5 in 2070), especially in the eastern Songnen Plain (SE) for the RCP8.5 scenarios.

Keywords Climate vegetation and productivity index . Potential productivity $\cdot$ Climate change

\section{Introduction}

Because forests are so important as carbon (C) sinks for mitigating climate change and provide other essential ecosystem services (Chapin et al. 2008; Coomes et al. 2014), climate warming is expected to directly influence forest structure and functions, such as productivity, by altering abiotic conditions (e.g., temperature, precipitation and atmospheric $\mathrm{CO}_{2}$ concentration) (Morin et al. 2018; Correia et al. 2018; Wang et al. 2019). This effect is especially considerable in boreal forests of China (Fang and Wang 2001; Fang et al. 2003, 2017; Gao et al. 2017) because tree establishment and growth in this kind of ecosystem will be significantly altered as climate changes further. Therefore, it is necessary to understand how boreal forest ecosystems will respond to the future climate change.

Although increased forest productivity has been reported (Fang et al. 2003; Boisvenue and Running 2010; Hember et al. 2012), other studies have found reduced productivity in temperate and boreal forests in continental dry climates (Barber et al. 2000; Verbyla 2011; Chen and Luo 2015; Walker et al. 2015; Zhang et al. 2015; Girardin et al. 2016), mostly due to the severe droughts induced by 
warming. Because the climatic factors constraining (temperature, precipitation and radiation) forest productivity varies in different parts of the world (Churkina and Running 1998; Nemani et al. 2003; Boisvenue and Running 2010), predictions of the effects of climate change on forest productivity still require more validation (Matias et al. 2017)

In addition, accurately estimating and modelling potential forest productivity (PP) at different scales are central elements of forest management and planning (Benavides et al. 2009; Berrill and O'Hara 2013; Duan et al. 2018). They provide critical information to forecast rates of change and estimate potential forest production under climate change. A variety of modelling approaches have been used to evaluate forest productivity using a wide range of environmental and stand variables (Corona et al. 1998; Bergès et al. 2005; Jiang et al. 2015; Duan et al. 2018). A general approach may be either phytocentric, considering production as the ultimate measure of site productivity, or geocentric, considering site productivity dependent on climatic and soil variables (Benavides et al. 2009). However, the site index is linked to a specific species and forest structure (Monserud and Sterba 1996; Bravo and Montero 2003; Benavides et al. 2009).

Therefore, the site index seems to be an inappropriate tool for non-forest land (Ung et al. 2001) and for young stands since a slight error in estimation at this age could lead to a much larger error (Bailey and Cieszewski 1992). Other studies in China have used remote sensing models to assess net primary production (NPP) (Piao et al. 2005; Wang et al. 2010; Pan and Zhen 2015; Piao et al. 2015). However, remote sensing data contain other factors in addition to climate, for example, air pollution, land-use change, the potential of regional forest productivity cannot be really reflected. Therefore, selecting an appropriate modeling method to estimate forest potential productivity is essential for forest management and better prediction of ecological consequences of climate change on forest in the future (Landsberg 2003).

The potential productivity of a vegetation on a site depends on the maximum sustained utilization of the environmental resources. Paterson (1956) developed the Climate Vegetation Productivity (CVP) index, which has become a valuable method for evaluating potential productivity of any forested vegetation by correlating climate and productivity. Productivity is described as volume increment per year, which is directly linked to growth and yield in forest management. Paterson showed that the forest productivity of a site is mainly determined by climatic factors, e.g., solar radiation, favorable temperature, precipitation and number of vegetation active months in any regions, where the climate has had enough time to develop soils (Nabuurs 1998). The CVP index was designed to predict the maximum growth potential in terms of volume production (Hägglund 1981). The index has been widely used by forest managers in Spain (Benavides et al. 2009), Australia (Howden and Gorman 1999), Pakistan (Champion et al. 1965), Bangladesh (Rahman et al. 2015) and so on with acceptable results at regional scales (Vanclay 1992). But the CVP index has not been assessed or used in China.

In this study, we used the CVP index model to evaluate the spatial variation of forest potential productivity in northeastern China and predict the possible consequences of future climate on it. First, the model was validated by comparing the average and maximum net primary production (NPP) values calculated by the model of light energy utilization (GLO_PEM). Then, the CVP index was used to simulate and predict forest potential productivity in Jilin Province in northeastern China under future climate scenarios.

\section{Materials and methods}

\section{Study area}

The study was done in Jilin Province in northeastern China from $40^{\circ} 52^{\prime}$ to $46^{\circ} 18^{\prime} \mathrm{N}, 121^{\circ} 38^{\prime}-131^{\circ} 19^{\prime} \mathrm{E}$ with an area of $21,3150 \mathrm{~km}^{2}$, comprising three subregions, including the southern Changbai Mountain (CB), eastern Songnen Plain (SE) and western Songnen Plain (SW) (Fig. 1). As one of the most important natural forest regions in China, the forests in the province provide timber and ecological services. The climate, controlled by high latitude East Asia monsoon, is temperate continental with warm summers, cold winters, abundant precipitation and a short growing season. Annual mean temperature is about $3.8^{\circ} \mathrm{C}$ in $\mathrm{CB}$, $5.1^{\circ} \mathrm{C}$ in SE and $5.6^{\circ} \mathrm{C}$ in SW. The average annual precipitation is about $703 \mathrm{~mm}$ in CB, $551 \mathrm{~mm}$ in SE and $442 \mathrm{~mm}$ in SW. The temperature and total precipitation is expected to increase by around $0.6,1.6,2.4{ }^{\circ} \mathrm{C}$ and $2.3,6.2$, $9.0 \%$ in the years 2020, 2050, and 2070, respectively (Wang et al. 2011). These climate changes will have potential effects on forest ecosystems.

\section{Data}

Climate data, including annual mean temperature, annual precipitation, maximum temperature of warmest month, temperature fluctuation (difference between mean monthly maximum temperature and minimum temperature) and solar radiation during "present" (1970-2000) and future (2050 and 2070) climate were extracted from the WorldClim-Global Climate Data (http://www.worldclim.org/) at a spatial resolution of $1 \mathrm{~km} \times 1 \mathrm{~km}$. Four greenhouse gas 
Fig. 1 Randomly selected sites in Jilin Province. No. 1-No. 10 represent the 10 times selected sites

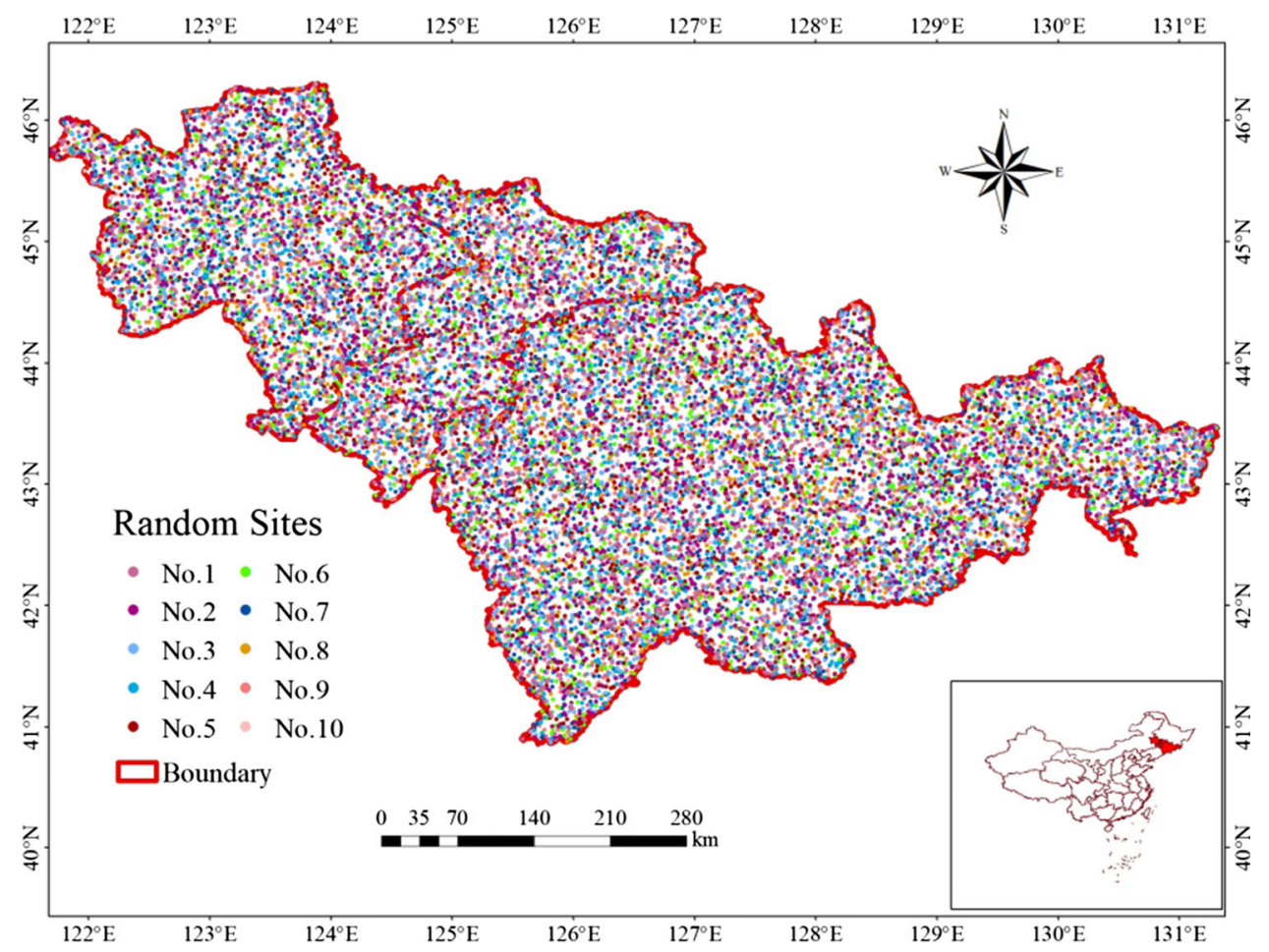

emissions scenarios for future climate were selected (CCSM4-RCP2.6, RCP4.5, RCP6.0, and RCP8.5; Table 1), which indicated that the temperatures in forest areas of China were projected to increase by between $1.1^{\circ} \mathrm{C}$ under RCP2.6 and $3.5{ }^{\circ} \mathrm{C}$ under RCP 8.5 relative to the average temperature during the baseline period of 1970-2000.

The NPP (Net Primary Productivity) data set (2000-2010) was downloaded from the Data Center for Resources and Environmental Sciences, Chinese Academy of Sciences (RESDC) (http://www.resdc.cn). NPP was calculated using the model of light energy utilization (GLO_PEM), which is based on the linear relation of light energy utilization between GPP (Gross Primary Productivity) and APAR(Absorbed Photosynthetically Active Radiation) (Prince and Goward 1995), and the following equations:

$N P P=G P P-R_{a}$

$G P P=A P A R \times \varepsilon$

$A P A R=P A R \times F P A R$

$\varepsilon=\varepsilon^{*} \times \sigma_{T} \times \sigma_{E} \times \sigma_{S}$ where PAR is photosynthetic active radiation, FPAR is the ratio of photosynthetic effective radiation absorbed by vegetation, $\varepsilon$ is realistic light energy utilization, $R_{\mathrm{a}}$ is aerobic respiration of vegetation, $\varepsilon^{*}$ is potential photosynthetic rate of vegetation, and $\sigma_{\mathrm{T}}, \sigma_{\mathrm{E}}$, and $\sigma_{\mathrm{S}}$ are the effect coefficient of air temperature, atmospheric moisture and soil moisture loss on plant growth, respectively.

\section{Climatic productivity}

The CVP index developed by Paterson (1956) is given by Eq. 5:

$C V P=\frac{V \times P \times G \times E}{A \times 12}$

$I=\frac{12 \times P}{T+10}$

where $V$ is the maximum temperature in the warmest month $\left({ }^{\circ} \mathrm{C}\right) ; A$ is the temperature fluctuation (difference between the mean monthly maximum temperature and minimum temperature, ${ }^{\circ} \mathrm{C}$ ); $P$ is the annual precipitation
Table 1 Warming increase $\left({ }^{\circ} \mathrm{C}\right)$ projections for Jilin Province according to four climate scenarios from the IPCC Fifth Assessment Report (AR5)

\begin{tabular}{lll}
\hline Future climate scenarios & Warming increase (2050) & Warming increase (2070) \\
\hline CCSM4-rcp2.6 & $1.3(0.3-2.2)$ & $1.1(0.1-2.0)$ \\
CCSM4-rcp4.5 & $1.7(0.7-2.9)$ & $2.1(1.1-2.6)$ \\
CCSM4-rcp6.0 & $1.5(0.5-2.3)$ & $2.1(1.1-3.0)$ \\
CCSM4-rcp8.5 & $2.4(1.3-3.2)$ & $3.5(2.4-4.3)$ \\
\hline
\end{tabular}


(mm); $T$ is the annual mean temperature; $G$ is the length of the growing season (months), according to Gaussen criteria (1954) using De Martonne aridity index $\left(I, \mathrm{~mm} /{ }^{\circ} \mathrm{C}\right)$, that is, with only humid months having an index above 20 included in the growing months, as long as this temperature is equal to or exceeds a minimum threshold of $6{ }^{\circ} \mathrm{C}$ (Eq. 6); and $E$ (insolation coefficient) is the radiation received at the pole expressed as a percentage of the radiation received at the latitude in question. The variables $A, V, P, E$ and $G$ (required for the CVP index) in Jilin Province were mapped (Fig. 2a-e), and summary statistics are listed in Table 2.

The relationship between the CVP index and PP was assessed using Eq. (7), developed by Paterson (1956) and validated for the FAO and other working parties, and given as $\mathrm{m}^{3} \mathrm{ha}^{-1}$ year $^{-1}$ :

$y=5.20 \log x-7.25$

where $x$ is the $C V P$ index and $y$ is the forest PP (maximum mean annual increment by stand volume).
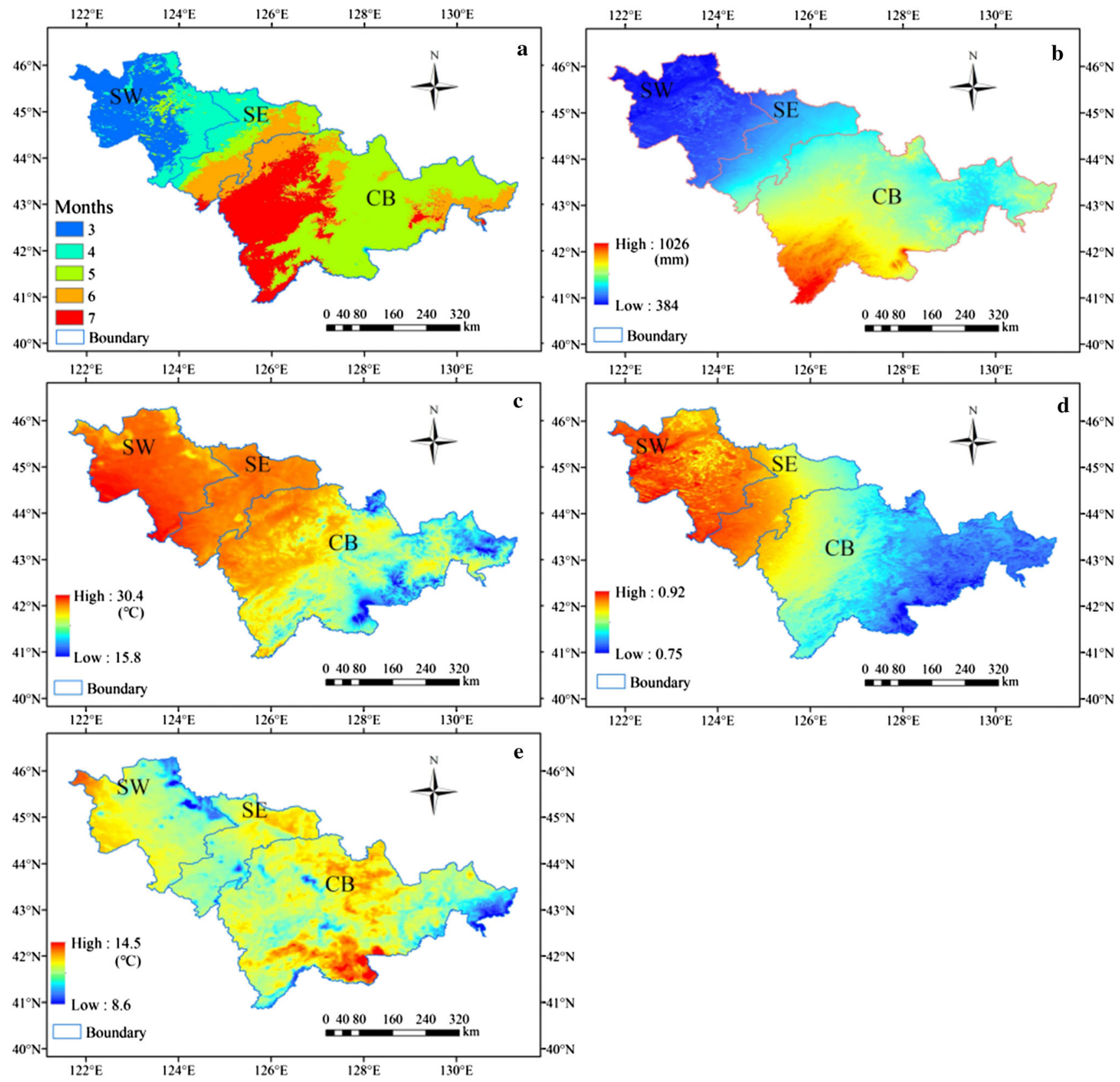

Fig. 2 Spatial pattern of input values to estimate Paterson's Climate Vegetation Productivity index for Jilin province (SW: western Songnen Plain, SE: eastern Songnen Plain, CB: southern Changbai

Mountain). a length of growing season (months); b annual precipitation $(\mathrm{mm})$; c maximum temperature of warmest month $\left({ }^{\circ} \mathrm{C}\right)$; d insolation coefficient $(E)$; e temperature fluctuation $\left({ }^{\circ} \mathrm{C}\right)$ 
Table 2 Climate variables in different subregions of Jilin Province

\begin{tabular}{|c|c|c|c|c|c|c|c|c|c|c|c|c|}
\hline \multirow[t]{2}{*}{ Variable } & \multicolumn{4}{|l|}{$\mathrm{CB}$} & \multicolumn{4}{|l|}{ SE } & \multicolumn{4}{|l|}{ SW } \\
\hline & Min & Mean & $\operatorname{Max}$ & SD & Min & Mean & $\operatorname{Max}$ & SD & Min & Mean & $\operatorname{Max}$ & SD \\
\hline$E$ & 0.75 & 0.82 & 0.88 & 0.02 & 0.82 & 0.87 & 0.90 & 0.02 & 0.85 & 0.89 & 0.92 & 0.01 \\
\hline$V\left({ }^{\circ} \mathrm{C}\right)$ & 15.8 & 26.8 & 29.6 & 1.6 & 28 & 29.1 & 30 & 0.3 & 27.2 & 29.4 & 30.4 & 0.5 \\
\hline$A\left({ }^{\circ} \mathrm{C}\right)$ & 8.8 & 11.9 & 14.5 & 0.6 & 9.9 & 11.8 & 12.7 & 0.4 & 8.6 & 11.7 & 13.2 & 0.6 \\
\hline$P(\mathrm{~mm})$ & 540 & 703 & 1026 & 94 & 445 & 551 & 680 & 41 & 388 & 442 & 533 & 28 \\
\hline$G$ (no.) & 3 & 5.8 & 7 & 0.9 & 4 & 5 & 7 & 0.9 & 3 & 3.4 & 7 & 0.6 \\
\hline
\end{tabular}

Three subregions, including southern Changbai Mountain (CB), eastern Songnen Plain (SE) and western Songnen Plain (SW); min, minimum; max, maximum; $E$, insolation coefficient; $V$, max temperature of warmest month; $A$, temperature fluctuation; $P$, annual precipitation; $G$, length of growing season (months)

\section{Statistical analyses}

The relationship between PP estimated from the CVP index and NPP observed in field (the mean and maximum NPP from 2000 to 2010) was examined to validate the reliability of PP values. Values for 2000 sites (10 times repeated) were randomly selected from the PP and NPP maps across the Jilin province (Fig. 1). To assess and spatially model these ecological variables, ArcGIS 10.2 was used (http:// www.esri.com/).

\section{Results}

\section{Spatial variation and relationship between PP and NPP}

Spatial heterogeneity of PP were found across Jilin Province (Fig. 3a), showing an increasing tendency from the lowest values $\left(5.45 \pm 0.49 \mathrm{~m}^{3} \mathrm{ha}^{-1} \mathrm{a}^{-1}\right)$ in the $\mathrm{SW}$, through the intermediate $\left(6.47 \pm 0.55 \mathrm{~m}^{3} \mathrm{ha}^{-1} \mathrm{a}^{-1}\right)$ in the northwest to the highest $\left(7.26 \pm 0.64 \mathrm{~m}^{3} \mathrm{ha}^{-1} \mathrm{a}^{-1}\right)$ in the southeast (SW-SE-CB, Table 3). The CVP index and PP ranged from 193.2-1264.3 and 4.6-8.9 $\mathrm{m}^{3} \mathrm{ha}^{-1} \mathrm{a}^{-1}$, respectively (Fig. 3a, b).

Power functions well described the relationships between PP and mean and maximum NPP. Coefficients of determination $\left(R^{2}\right)$ of mean NPP and PP $(0.586-0.633)$ were higher than for PP and maximum NPP (0.318-0.395) (Figs. 4, 5) $(P<0.0001)$. The values of PP showed a significant positive relationship with both mean and maximum NPP values in Jilin Province, and the correlation is medium and not high as expected.

\section{Climate change effects on potential forest productivity}

Potential productivity was significantly $(P<0.0001)$ correlated with the length of the growing season, precipitation, insolation coefficient and maximum temperature in the warmest month (Fig. 6). PP increased with growing season length and precipitation, first increasing and then decreasing with the insolation coefficient and warmest temperature, but no significant relationship was found for temperature fluctuation.
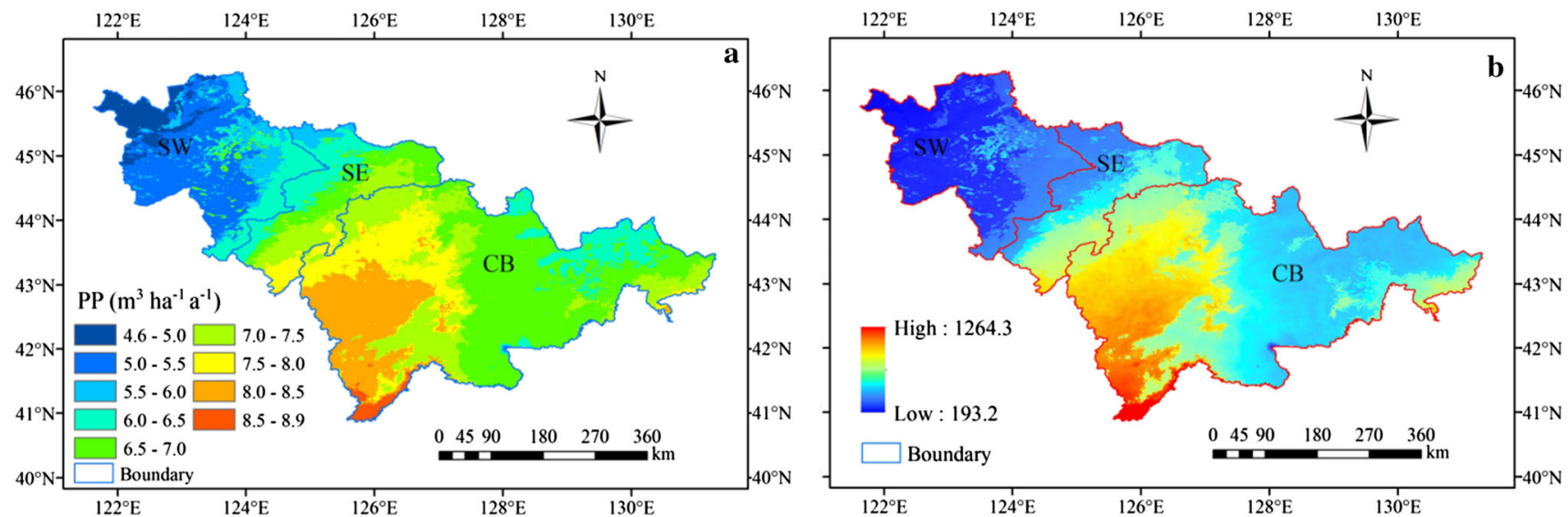

Fig. 3 Spatial pattern of potential productivity $\left(\mathrm{PP}, \mathrm{m}^{3} \mathrm{ha}^{-1} \mathrm{a}^{-1}\right)$ (a) and Paterson's Climate Vegetation Productivity index (b) in Jilin province (SW: western Songnen Plain, SE: eastern Songnen Plain, CB: southern Changbai Mountain) 
Table 3 Potential productivity (PP) and change in PP in three subregions in Jilin Province under future climate scenarios (RCP2.6 and RCP 8.5)

\begin{tabular}{|c|c|c|c|c|c|c|c|c|c|}
\hline \multirow[t]{2}{*}{ Scenario } & \multicolumn{3}{|c|}{$\mathrm{CB}\left(\mathrm{m}^{3} \mathrm{ha}^{-1} \mathrm{a}^{-1}\right)$} & \multicolumn{3}{|c|}{$\operatorname{SE}\left(\mathrm{m}^{3} \mathrm{ha}^{-1} \mathrm{a}^{-1}\right)$} & \multicolumn{3}{|c|}{$\mathrm{SW}\left(\mathrm{m}^{3} \mathrm{ha}^{-1} \mathrm{a}^{-1}\right)$} \\
\hline & Mean PP & $\Delta \mathrm{PP}(\%)$ & SD & Mean & $\Delta \mathrm{PP}(\%)$ & SD & Mean & $\Delta \mathrm{PP}(\%)$ & SD \\
\hline Present & 7.26 & & 0.64 & 6.47 & & 0.55 & 5.45 & & 0.49 \\
\hline RCP2.6-2050 & 7.36 & 1.38 & 0.63 & 7 & 8.19 & 0.54 & 5.64 & 3.49 & 0.44 \\
\hline RCP8.5-2050 & 7.70 & 6.06 & 0.62 & 7.26 & 12.21 & 0.59 & 5.85 & 7.34 & 0.45 \\
\hline RCP2.6-2070 & 7.37 & 1.52 & 0.61 & 7.01 & 8.34 & 0.57 & 5.61 & 2.94 & 0.45 \\
\hline RCP8.5-2070 & 7.94 & 9.36 & 0.61 & 7.46 & 15.30 & 0.58 & 6.08 & 11.56 & 0.44 \\
\hline
\end{tabular}

Three subregions, including southern Changbai Mountain (CB), eastern Songnen Plain (SE) and western Songnen Plain (SW)
Table 3 shows that PP in the three subregions of Jilin Province under future climate scenarios. Compared with the present climate, PP in all the subregion sites would increase under the future climate change, but the increment in PP varied with both warming scenarios and the subregion sites (Fig. 7). In this paper, the RCP2.6 and RCP8.5 scenarios, representing the mean minimum of warming $\left(1.3{ }^{\circ} \mathrm{C}\right.$ in $2050,1.1^{\circ} \mathrm{C}$ in 2070$)$ and mean maximum of warming $\left(2.4{ }^{\circ} \mathrm{C}\right.$ in $2050,3.5^{\circ} \mathrm{C}$ in 2070$)$, were selected to analyze the variation in PP under climate change.

The largest increase in mean PP was in region SE across all warming scenarios (Fig. 8), which amounted to $8.19 \%$ $\left(0.53 \mathrm{~m}^{3} \mathrm{ha}^{-1} \mathrm{a}^{-1}\right)$ in 2050 and $8.34 \%\left(0.54 \mathrm{~m}^{3} \mathrm{ha}^{-1} \mathrm{a}^{-1}\right)$ in 2070 for the RCP2.6 scenarios, $12.21 \%$ $\left(0.79 \mathrm{~m}^{3} \mathrm{ha}^{-1} \mathrm{a}^{-1}\right)$ in 2050 and $15.30 \%$ $\left(0.99 \mathrm{~m}^{3} \mathrm{ha}^{-1} \mathrm{a}^{-1}\right)$ in 2070 for the RCP8.5 scenarios compared with the present (Table 3). The largest increase in mean precipitation also was in the SE, which amounted to $38.5 \%(170 \mathrm{~mm})$ to $55.7 \%(24 \mathrm{~mm})$, although the maximum temperature increment $(0-7.8 \%)$ was smaller than in the CB (0.4-9.3\%) and SW (1.7-9.6\%) (Table 4). The minimum increase in mean PP was in the CB (Fig. 8), with $1.38 \%\left(0.10 \mathrm{~m}^{3} \mathrm{ha}^{-1} \mathrm{a}^{-1}\right)$ in 2050 and $1.52 \%$ $\left(0.11 \mathrm{~m}^{3} \mathrm{ha}^{-1} \mathrm{a}^{-1}\right)$ in 2070 for the RCP2.6 scenarios and $6.06 \%\left(0.44 \mathrm{~m}^{3} \mathrm{ha}^{-1} \mathrm{a}^{-1}\right)$ in 2050 and $9.36 \%$ $\left(0.68 \mathrm{~m}^{3} \mathrm{ha}^{-1} \mathrm{a}^{-1}\right)$ in 2070 for RCP8.5 scenarios (Table 4). Although mean precipitation increment in the CB (8.3-20.9\%) was larger than in the SE $(-2.7$ to $13.4 \%$ ), the maximum temperature rise was smaller (0.4-9.3\% in CB, 1.7-9.6\% in SW) than in SE (Table 4).

\section{Discussion}

\section{Potential productivity modelling}

In forestry studies, forest site productivity is evaluated with the help of different indices. Site index is most frequently used, but it is tree species-dependent (Sajjaduzzaman et al. 2005) and is difficult for uneven-aged and young forests
(Weiskittel et al. 2011). There is no single index based directly on climate parameters that is sufficiently precise for forest management and modeling (Rahman and Akter 2015). The CVP index model could be better for predicting PP using only climate factors (Kant 2005). As a vegetationfree index, it is the key process to determine vegetation productivity potential in any region according to climatic parameters although the index cannot completely explain the site quality of specific forest sites. This approach has been widely used for afforestation planning in Spain, together with other more specific studies, focused on evaluating the site potentiality for forests (Benavides et al. 2009). However, the CVP index has not been assessed or used in China. Owing to the lack of data on forest PP generated from permanent sample plots at a large scale, we validated the CVP index-based PP against mean and maximum NPP for Jilin Province in northeastern China by analyzing forest PP based on the CVP index and found that PP was moderately significantly correlated with NPP. The pattern of PP was consistent with climatic gradients; thus, the approach is partially valid for predicting PP of forests in northeastern China with the coefficients of determination from 0.318 to 0.633 between PP and NPP. There is no acceptable method to quantifying forest $\mathrm{PP}$, and the results are also dependent on the accuracy of the climate data. Therefore, more validation is needed to further examine the parameters describing the relationship between CVP index and PP in the model.

\section{Climate effects on forest potential productivity}

Although all biological activity in a forest is ultimately dependent on absorbed solar radiation, solar radiation alone obviously does not determine forest PP (Boisvenue and Running 2010). Our results indicated that the insolation coefficient $(E)$, precipitation and length of the growing season were the major factors controlling forest PP in northeastern China. The forest PP presented the peak curve with the insolation coefficient and warmest temperature. One possible explanation for our results is that increasing 
Fig. 4 Relationship between potential productivity (PP) and mean NPP for 2000-2010 $(N=2000)$. $\mathbf{a}-\mathbf{j}$ The 10 times randomly selected sites
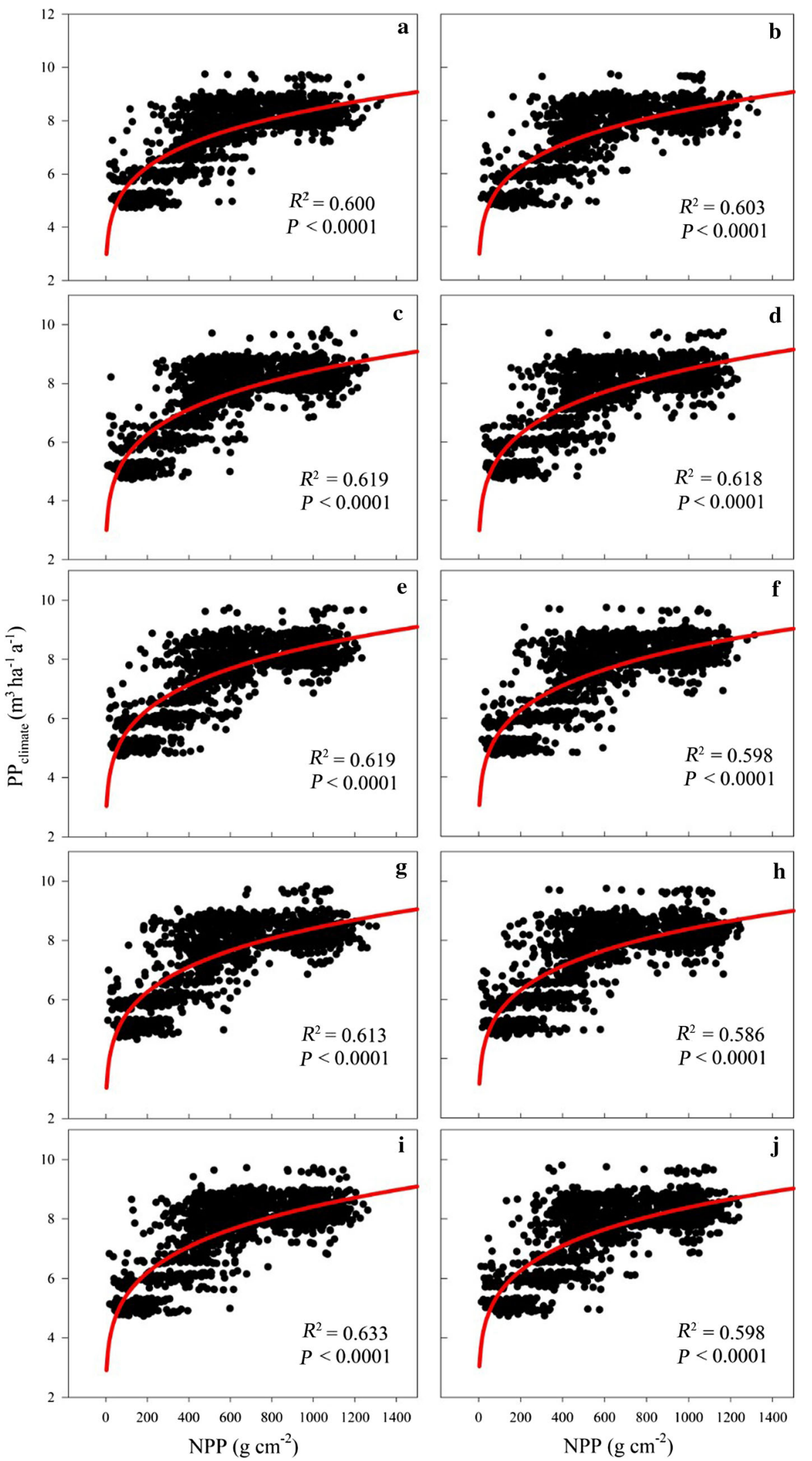
Fig. 5 Relationship between potential productivity (PP) and maximum NPP from 2000 to $2010(\mathrm{~N}=2000)$. $\mathbf{a}-\mathbf{j}$ The 10 times randomly selected sites

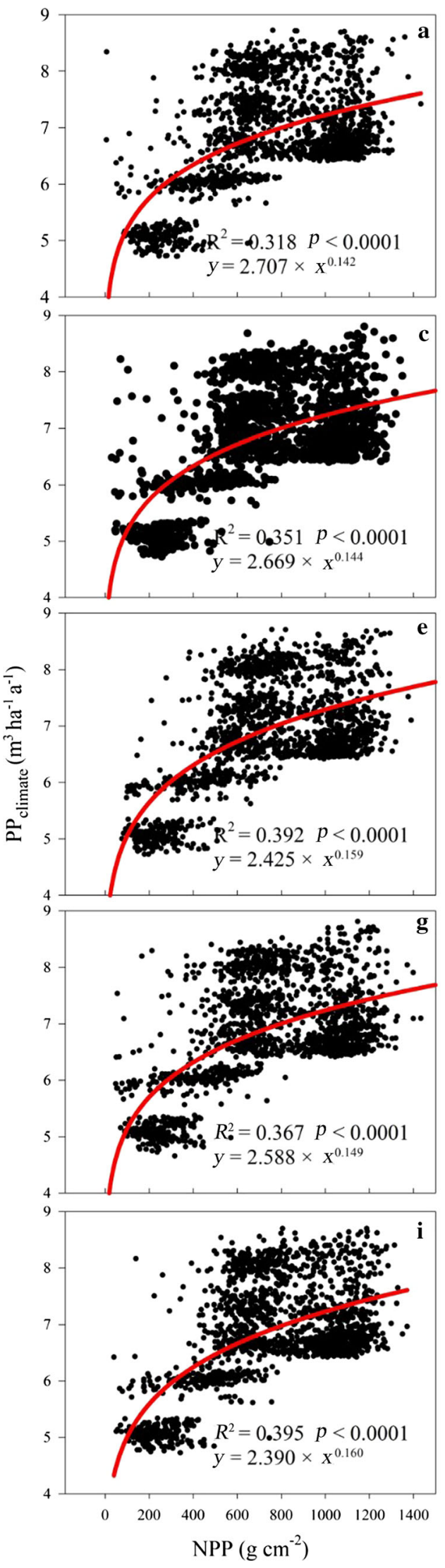

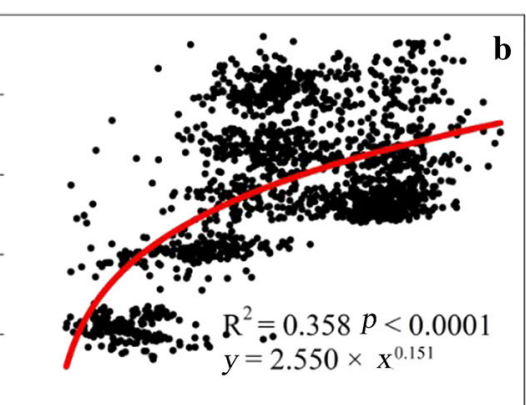
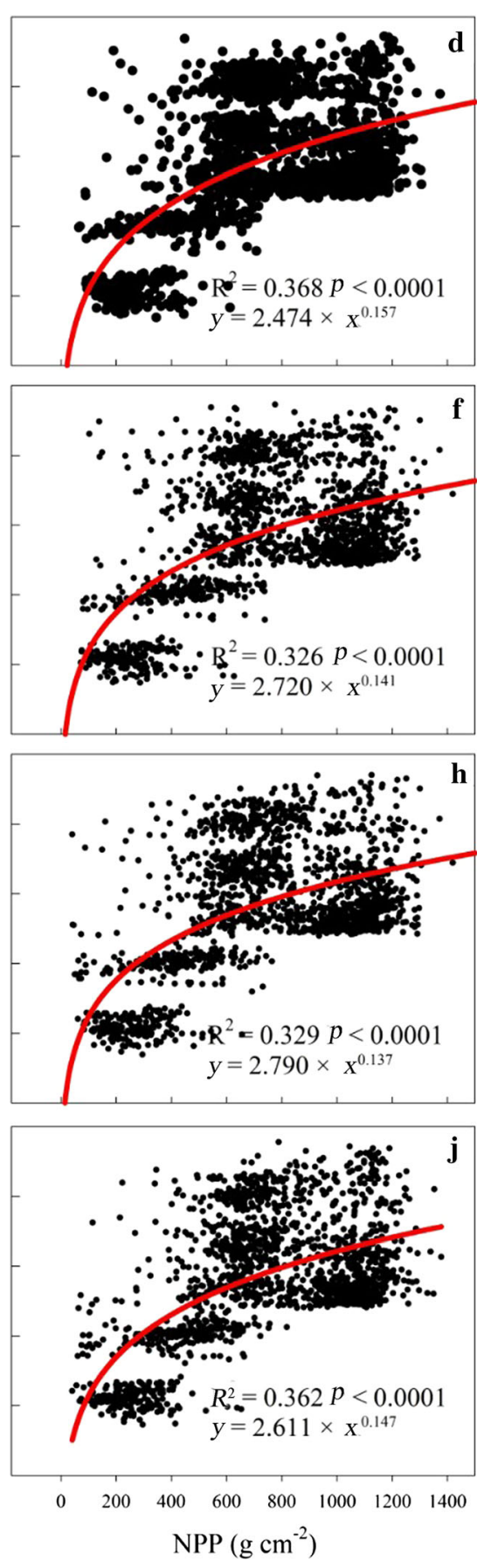
Fig. 6 The relationship between the PP and Climate factors $(N=2000)$ : a length of growing season (months); b insolation coefficient; c temperature fluctuation (bio2); d annual precipitation;

e warmest temperature (bio5)
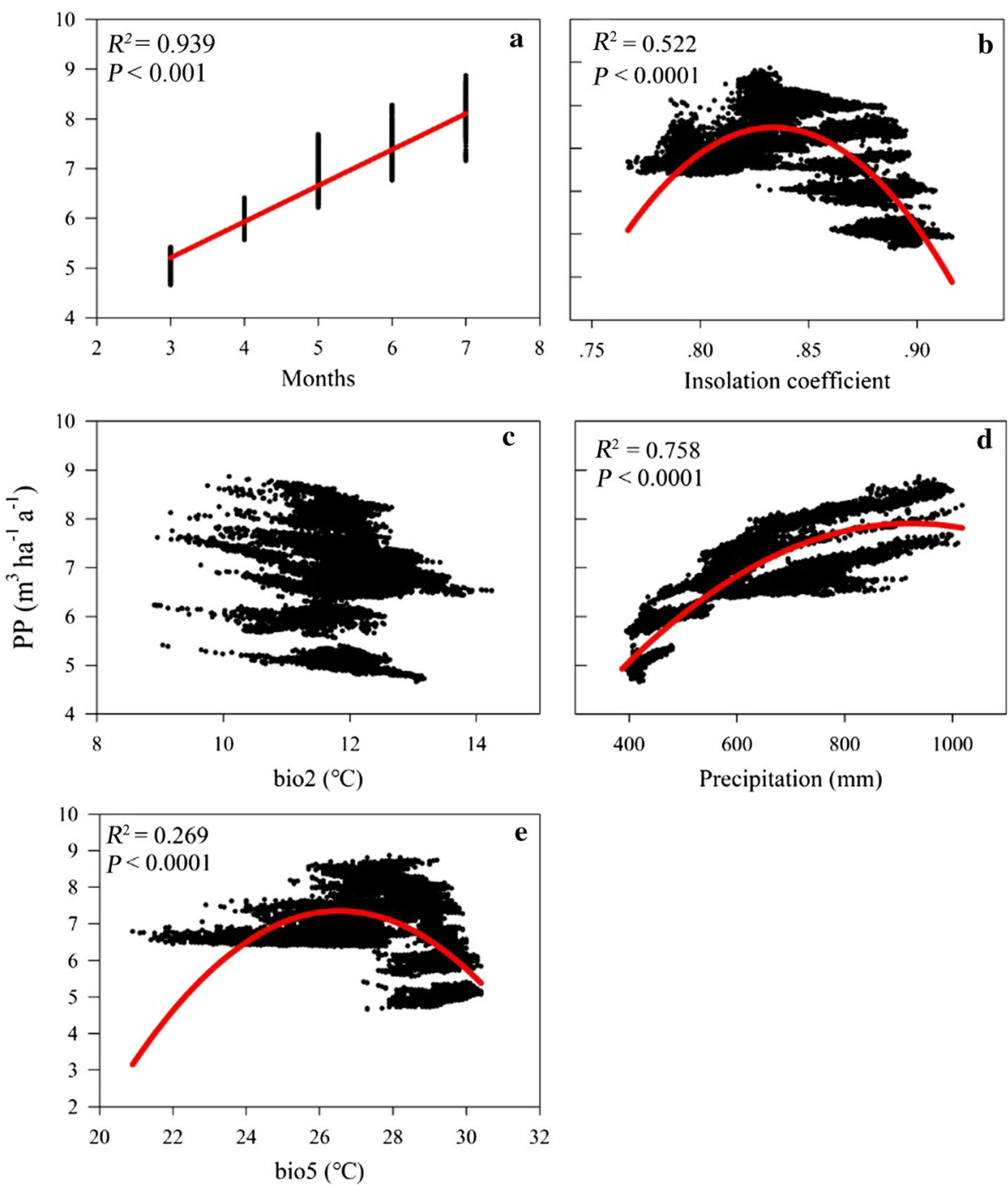

Precipitation $(\mathrm{mm})$ solar radiation may also increase the temperature and vapor pressure deficit of the air, and thereby increase transpiration rates, resulting in adverse effects when beyond the maximum photosynthetic utilization (Benavides et al. 2009). However, the value of $E$ in our study decreased in order from CB to SE to SW, which was inconsistent with the PP pattern, indicating that the insolation coefficient was not the major influence on variation in forest PP in northeastern China.

Our result indicated that the PP was positively correlated with precipitation, which is consistent with the result of $\mathrm{He}$ et al. (2015) who found that the NPP of a Larix olgensis forest in northeastern China was significantly correlated with annual precipitation. Knapp and Smith (2001) also found that the aboveground NPP was significantly correlated with annual precipitation across North America. In Jilin Province in northeastern China, the PP pattern was consistent with that of the precipitation, and both were higher in CB than in SW and SE (Figs. 2b, 3a). Liu et al.
(2005) found that the forest grows fastest in CB mountain region than in other forest regions of northeastern China. These results indicated that precipitation was the major control factors of forest PP variation in Jilin Province. Wang (2006) further indicated that variation in NPP in northeastern China was significantly correlated with precipitation and temperature.

The length of the growing period can be often used to assess the crop production potential because it represents an area within which temperature and precipitation conditions are suitable for crop growth for a given number of days in the year (FAO 1996). Pretzsch et al. (2011) found that an extension of the growing season can benefit forest growth in alpine areas of Central Europe. These results are similar with our study, showing that forest PP was positively correlated with the length of the growing season; that is, the longer the growing period the higher the productivity of the forest. 

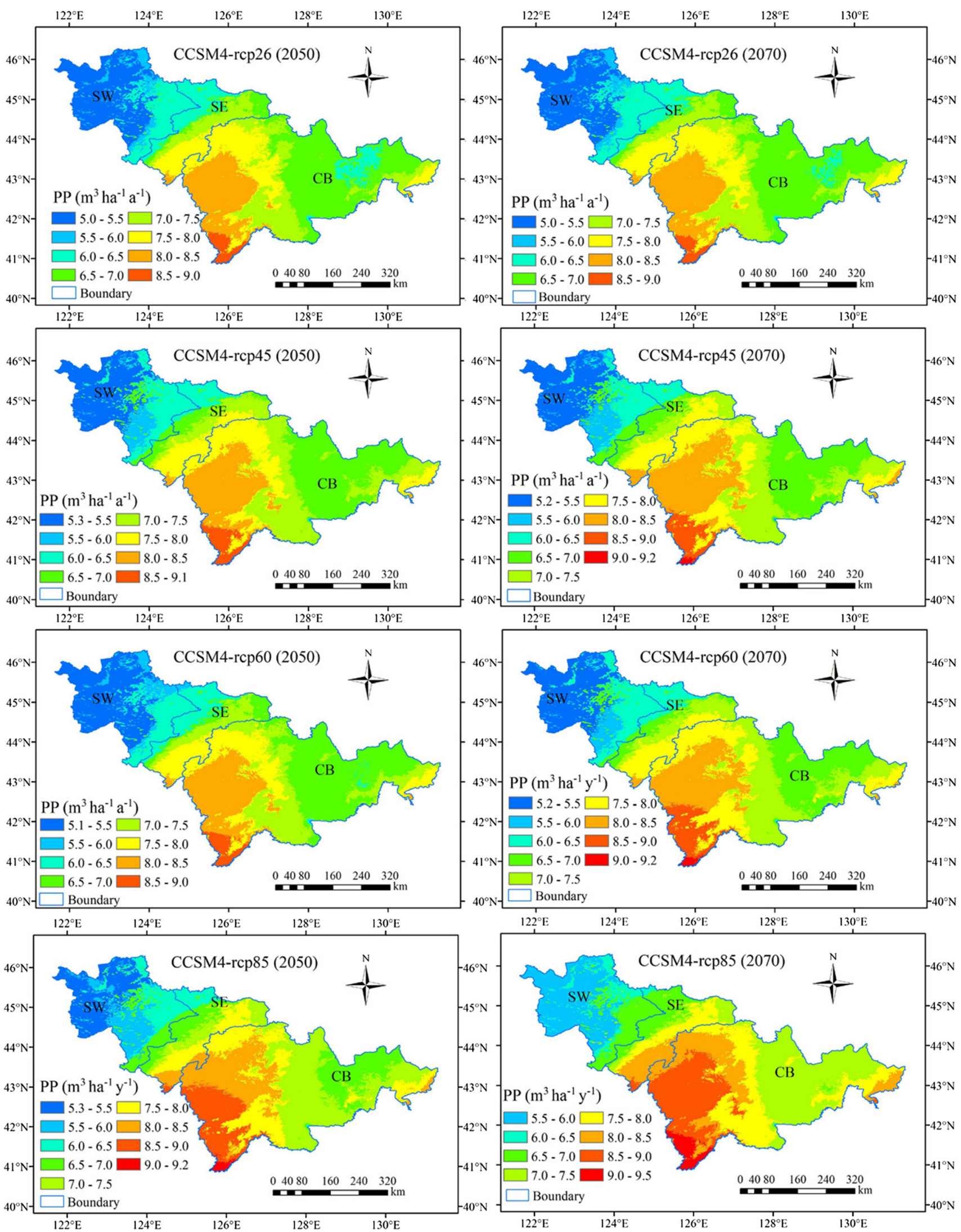
4Fig. 7 Potential productivity (PP) predicted by the CVP index model for different subregions (SW: western Songnen Plain, SE: eastern Songnen Plain, CB: southern Changbai Mountain) in Jilin province in 2050 (left panel) and 2070 (right panel) under four climate change scenarios (RCP 2.6, 4.5, 6.0 and 8.5)

Meanwhile, temperature controls the rate of plant metabolism and thus photosynthesis (Rahman et al. 2015). Our study showed, however, that temperature fluctuation was not correlated with PP; temperature and precipitation regime were more relevant when calculated for the length of the growing season.

Our results indicated dramatic spatial heterogeneity in PP across Jilin Province; PP gradually decreased from east to west consistent with the increasing NPP from west to east in western Jilin Province (Tang et al. 2013). The lower $\mathrm{PP}$ in the western (SW) zone resulted from the higher solar
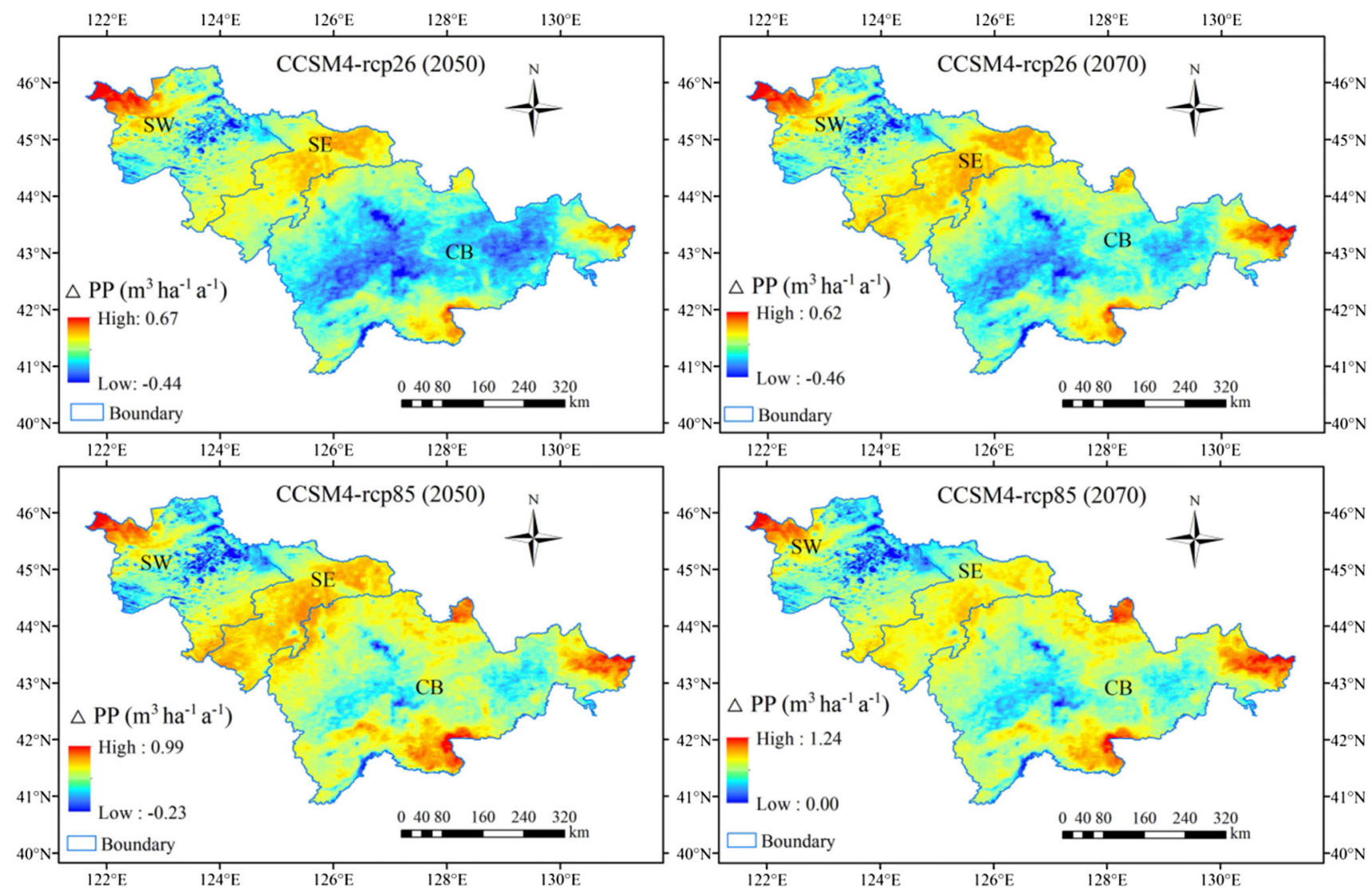

Fig. 8 Potential productivity (PP) increments under two future climate scenarios (RCP2.6 and RCP 8.5) in different subregions (SW: western Songnen Plain, SE: eastern Songnen Plain, CB: southern Changbai Mountain) in Jilin Province in 2050 (left panel) and 2070 (right panel)

Table 4 Future climate scenarios and its increment in three subregions in Jilin province

\begin{tabular}{|c|c|c|c|c|c|c|c|c|c|c|}
\hline \multirow[t]{2}{*}{ Scenario } & \multirow[t]{2}{*}{ Year } & \multicolumn{3}{|l|}{$\mathrm{CB}$} & \multicolumn{3}{|l|}{ SE } & \multicolumn{3}{|l|}{ SW } \\
\hline & & Mean & $\Delta T(P)$ & SD & Mean & $\Delta T(P)$ & SD & Mean & $\Delta T(P)$ & SD \\
\hline MaxT-RCP2.6 & 2050 & 27 & 0.7 & 17.5 & 29.4 & 0 & 2.6 & 29.7 & 2.1 & 2.6 \\
\hline MaxT-RCP2.6 & 2070 & 26.9 & 0.4 & 17.5 & 29.4 & 0 & 3.4 & 29.6 & 1.7 & 2.5 \\
\hline MaxT-RCP8.5 & 2050 & 28.2 & 5.2 & 17.7 & 30.6 & 4.1 & 2.3 & 30.8 & 5.8 & 2.7 \\
\hline MaxT-RCP8.5 & 2070 & 29.3 & 9.3 & 17.4 & 31.7 & 7.8 & 2.4 & 31.9 & 9.6 & 2.5 \\
\hline P-RCP2.6 & 2050 & 761 & 8.3 & 107.8 & 612 & 38.5 & 50 & 478 & -13.2 & 29.2 \\
\hline P-RCP2.6 & 2070 & 767 & 9.1 & 98 & 618 & 39.8 & 53 & 477 & -13.4 & 33.1 \\
\hline P-RCP8.5 & 2050 & 814 & 15.7 & 106 & 650 & 47.1 & 58 & 502 & -8.9 & 37.3 \\
\hline P-RCP8.5 & 2070 & 850 & 20.9 & 108 & 688 & 55.7 & 61 & 536 & -2.7 & 38 \\
\hline
\end{tabular}

MaxT, maximum temperature $\left({ }^{\circ} \mathrm{C}\right) ; P$, precipitation $(\mathrm{mm}) ; \Delta T(P)$, the increment of maximum temperature and precipitation from present to future scenarios 
radiation, lower precipitation and the shorter growing period (Fig. 2a, b, d).

\section{Forest potential productivity under future climate change scenarios}

One objective of this study was to identify the possible signs and magnitude of forest PP changes in response to future climate change across Jilin Province in northeastern China during the 21st century. Our results indicated that PP across Jilin Province gradually increased under all tested RCP scenarios (2050 and 2070), especially the RCP8.5 scenario. These results were consistent with the analysis of satellite data accompanied by process-based modelling showed that the NPP in China increased between 1982 and 1999 (Fang et al. 2003). Zhao et al. (2008) found that NPP of a forest in northeastern China would increase $9.37 \%$ with a temperature increase of $3{ }^{\circ} \mathrm{C}$ using the forest carbon budget model FORCCHN that is based on the growth of individual trees, and Peng et al. (2009) predicted that climate change would increase forest NPP and biomass carbon under all three climate change scenarios in northeastern China based on the process-based forest growth model TRIPLEX. He et al. (2015) studied the response of NPP of a Larix olgensis forest in Jilin Province to climate change and found that the NPP would increase under the SRES A2 and B2 scenarios with increased temperature and $\mathrm{CO}_{2}$ concentration. Zhao et al. $(2009,2011)$ predicted that the NPP of coniferous and broad-leaf mixed forests in northeastern China had an increasing trend under future climate warming, using the GLOPEM-CEVSA model. Shen et al. (2015) studied the potential impacts of regional climate change on productivity of Larix olgensis in northeastern China using a generalized additive model (GAM) and found that the change of mean site productivity of Larix olgensis would vary from 2.2 to - 5.9\% by 2050 and from 3.7 to $-11.8 \%$ by 2070 under three BC-RCP scenarios with rising temperature and increasing precipitation. Although all RCPs scenario simulations indicated that forest PP would increase by the end of this century in response to future climate changes, the magnitude of this increase varies markedly among different areas (PP increased by $8.19-15.30 \%$ in SE, $1.38-9.36 \%$ in $\mathrm{CB}, 3.48-11.56 \%$ in SW from the present to 2070). For example, compared with the SE and SW, the PP in CB was the highest, but the increment in PP under future climate change was the lowest, and the increment in PP under future climate change in SE was the largest. The reason for the spatial variation in PP may include the following aspects. First, given the spatial heterogeneity of environment variables (e.g., temperature, precipitation) and the difference of climate change across study areas, the mean precipitation increase was larger in the SE than in the $\mathrm{CB}$ and SW. Second, the climate change scenario for the rise of atmospheric $\mathrm{CO}_{2}$ concentration on the one hand can increase the temperature; on the other hand, it can have a fertilizer effect. For example, Peng et al. (2009) found that the combined effects of climate change and $\mathrm{CO}_{2}$ fertilization on the increase of NPP were estimated to be $10-12 \%$ for the 2030s and $28-37 \%$ for the 2090s, and Fang et al. (2017) indicated that the drought can be compensated by a $\mathrm{CO}_{2}$ fertilization effect on NPP in eastern China. In addition, increasing $\mathrm{CO}_{2}$ concentration also can decrease the wateruse efficiency in a forest (Cramer et al. 2001). As a result of such complex climate interaction effects and plant response patterns, there is no universal method to estimate climate change impacts on forest PP. Therefore, effective management strategies should be based on careful analysis of local climate change patterns.

\section{Conclusions}

With the rapid climate change in recent decades, assessing the impacts of climate factors on forest ecosystem productivity in northeastern China and elsewhere has become important. The CVP index model, which we first validated using NPP according to the model of light energy utilization (GLM_PEM), provided a valuable tool to evaluate the effects of climate change on the forest potential productivity in northeastern China. Our results showed that spatial variations in forest PP were influenced most by changes in precipitation, length of the growing season and insolation coefficient. The PP is expected to increase in response to future climate change scenarios by the end of this century. But the increment of change in PP under climate change scenarios varied in different areas, with the largest increase predicted in SE and the lowest in CB.

Open Access This article is distributed under the terms of the Creative Commons Attribution 4.0 International License (http://crea tivecommons.org/licenses/by/4.0/), which permits unrestricted use, distribution, and reproduction in any medium, provided you give appropriate credit to the original author(s) and the source, provide a link to the Creative Commons license, and indicate if changes were made.

\section{References}

Bailey RL, Cieszewski CJ (1992) Development of a well-behaved site-index equation: jack pine in north-central Ontario: comment. Can J For Res 30:1667-1668

Barber VA, Juday GP, Finney BP (2000) Reduced growth of Alaskan white spruce in the twentieth century from temperature-induced drought stress. Nature 405:668-673

Benavides R, Roig S, Osoro K (2009) Potential productivity of forested areas based on a biophysical model. A case study of a mountainous region in northern Spain. Ann For Sci 66:108 
Bergès L, Chevalier R, Dumas Y, Franc A, Gilbert JM (2005) Sessile oak (Quercus petraea) site index variations in relation to climate, topography and soil in even-aged high-forest stands in northern France. Ann For Sci 62:391-402

Berrill JP, O'Hara KL (2013) Estimating site productivity in irregular stand structures by indexing the basal area or volume increment of the dominant species. Can J For Res 44:92-100

Boisvenue C, Running SW (2010) Impacts of climate change on natural forest productivity-evidence since the middle of the 20th century. Glob Change Biol 12:862-882

Bravo F, Montero G (2003) High-grading effects on Scots pine volume and basal area in pure stands in northern Spain. Ann For Sci 60:11-18

Champion SHG, Seth SK, Khattak GM (1965) Manual of silviculture for Pakistan. Govt. Press, Islamabad

Chapin FS, Randerson JT, Mcguire AD, Foley JA, Field CB (2008) Changing feedbacks in the climate-biosphere system. Front Ecol Environ 6:313-320

Chen HY, Luo Y (2015) Net aboveground biomass declines of four major forest types with forest ageing and climate change in western Canada's boreal forests. Glob Change Biol 21:3675-3684

Churkina G, Running SW (1998) Contrasting climatic controls on the estimated productivity of global terrestrial biomes. Ecosystems $1: 206-215$

Coomes DA, Burslem DFRP, Simonson WD (2014) Forests and global change. Cambridge University Press, Cambridge

Corona P, Scotti R, Tarchiani N (1998) Relationship between environmental factors and site index in Douglas-fir plantations in central Italy. For Ecol Manag 110:195-207

Correia DLP, Raulier F, Bouchard M, Filotas É (2018) Response diversity, functional redundancy and post-logging productivity in northern temperate and boreal forests. Ecol Appl 28:1282-1291

Cramer W, Bondeau A, Woodward FI, Prentice IC, Betts RA, Brovkin V, Cox PM, Fisher V, Foley JA, Friend AD (2001) Global response of terrestrial ecosystem structure and function to $\mathrm{CO}_{2}$ and climate change: results from six dynamic global vegetation models. Glob Change Biol 7:357-373

Duan GS, Gao ZG, Wang QY, Fu LY (2018) Comparison of different height-diameter modelling techniques for prediction of site productivity in natural uneven-aged pure stands. Forests 9:63

Fang JY, Wang ZM (2001) Forest biomass estimation at regional and global levels, with special reference to China's forest biomass. Ecol Res 16:587-592

Fang J, Piao S, Field CB, Pan Y, Guo Q, Zhou L, Peng C, Tao S (2003) Increasing net primary production in China from 1982 to 1999. Front Ecol Environ 1:293-297

Fang X, Zhang C, Wang Q, Chen X, Ding J, Karamage F (2017) Isolating and quantifying the effects of climate and $\mathrm{CO}_{2}$ changes (1980-2014) on the net primary productivity in arid and semiarid China. Forests 8:60

FAO (1996) Agro-ecological zoning guidelines. FAO soils bulletin. Soil resources, management and conservation service, vol 76. Rome, Italy: FAO Land and Water Development Division, Food and Agriculture Organization of the United Nations

Gao WQ, Ni YY, Xue ZM, Wang XF, Kang FF, Hu J, Gao ZH, Jiang ZP, Liu JF (2017) Population structure and regeneration dynamics of Quercus variabilis along latitudinal and longitudinal gradients. Ecosphere 8(ecs2): 1737

Girardin MP, Bouriaud O, Hogg EH, Kurz W, Zimmermann NE, Metsaranta JM, De JR, Frank DC, Esper J, Büntgen U (2016) No growth stimulation of Canada's boreal forest under half-century of combined warming and $\mathrm{CO}_{2}$ fertilization. Proc Natl Acad Sci USA 113:E8406
Hägglund B (1981) Evaluation of forest site productivity. For Abstr Rev Artic 42:515-527

He LH, Wang HY, Wang L, Wang Y (2015) Response of net primary productivity of Larix olgensis forest ecosystem to climate change. J Beijing For Univ 37:28-36 (in Chinese with English abstract)

Hember RA, Kurz WA, Metsaranta JM, Black TA, Guy RD, Coops $\mathrm{NC}$ (2012) Accelerating regrowth of temperate-maritime forests due to environmental change. Glob Change Biol 18:2026-2040

Howden SM, Gorman JT (1999) Impacts of global change on Australian temperate forests. Csiro Wildlife Ecology Resource Futures Program, Australian

Jiang HQ, Radtkephilip J, Weiskittelaaron R, Coulstonjohn W, Guertinpatrick J (2015) Climate- and soil-based models of site productivity in eastern US tree. Can J For Res 45:325-342

Kant P (2005) Raising Kyoto forests in the different bio-geographic zones of India: a profitability analysis. Indian For 131:1105-1121

Knapp AK, Smith MD (2001) Variation among biomes in temporal dynamics of aboveground primary production. Science 291:481-484

Landsberg J (2003) Modelling forest ecosystems: state of the art, challenges, and future directions. Can J For Res 33:385-397

Liu X, Sun X, Xia C (2005) Assessing boreal forest productivity in China with a biogeographic process model (forest-BGPG). In: IEEE international geoscience and remote sensing symposium, IEEE

Matias L, Linares JC, Sanchez-Miranda A, Jump AS (2017) Contrasting growth forecasts across the geographical range of Scots pine due to altitudinal and latitudinal differences in climatic sensitivity. Glob Change Biol 23:4106-4116

Monserud RA, Sterba H (1996) A basal area increment model for individual trees growing in even- and uneven-aged forest stands in Austria. For Ecol Manag 80:57-80

Morin X, Fahse L, Jactel H, Schererlorenzen M, Garcíavaldés R, Bugmann H (2018) Long-term response of forest productivity to climate change is mostly driven by change in tree species composition. Sci Rep 8:5627

Nabuurs, GJ, Pajuoja H, Kuusela K, Paivinen R (1998) Forest resource scenario methodology for Europe. Discussion Paper No. 5, European Forest Institute, Joensuu, Finland

Nemani RR, Keeling CD, Hashimoto H, Jolly WM, Piper SC, Tucker CJ, Myneni RB, Running SW (2003) Climate-driven increases in global terrestrial net primary production from 1982 to 1999. Science 300:1560-1563

Pan JH, Zhen LI (2015) Temporal-spatial change of vegetation net primary productivity in the arid region of northwest China during 2001 and 2012. Chin J Ecol 34:3333-3340 (in Chinese with English abstract)

Paterson SS (1956) The forest area of the world and its potential productivity. Goteburg University Press, Goteburg

Peng C, Zhou X, Zhao S, Wang X, Zhu B, Piao S, Fang J (2009) Quantifying the response of forest carbon balance to future climate change in northeastern China: model validation and prediction. Glob Planet Change 66:179-194

Piao S, Fang J, Zhou L, Zhu B, Tan K, Tao S (2005) Changes in vegetation net primary productivity from 1982 to 1999 in China. Glob Biogeochem Cycles 19:GB2027

Piao S, Yin G, Tan J, Cheng L, Huang M, Li Y, Liu R, Mao J, Myneni RB, Peng S (2015) Detection and attribution of vegetation greening trend in China over the last 30 years. Glob Change Biol 21:1601-1609

Pretzsch H, Biber P, Schütze G, Uhl E, Rötzer T (2011) Forest stand growth dynamics in Central Europe have accelerated since 1870. Nat Commun 5:4967 
Prince SD, Goward SN (1995) Global primary production: a remote sensing approach. J Biogeogr 22:815-835

Rahman MS, Akter S (2015) Climate to forest productivity: implication of Paterson's CVP Index. Res J For 9:27-34

Rahman MS, Akter S, Al-Amin M (2015) Forest and agroecosystem productivity in Bangladesh: a climate vegetation productivity approach. For Sci Technol 11:126-132

Sajjaduzzaman M, Mollick AS, Mitlohner R, Muhammed N, Kamal MT (2005) Site index for teak (Tectona grandis Linn. F.) in forest plantations of Bangladesh. Int J Agric Biol 7:547-549

Shen C, Lei X, Liu H, Wang L, Liang W (2015) Potential impacts of regional climate change on site productivity of Larix olgensis plantations in northeast China. For Biogeosci For 8:642

Tang J, Jiang Y, Li ZY, Zhang N, Meng HU (2013) Estimation of vegetation net primary productivity and carbon sink in western Jilin province based on CASA model. J Arid Land Resourc Environ 27:1-7 (in Chinese with English abstract)

Ung C, Bernier PY, Raulier F, Fournier RA, Lambert M, Régnière J (2001) Biophysical site indices for shade tolerant and intolerant boreal species. For Sci 47:83-95

Vanclay JK (1992) Assessing site productivity in tropical moist forests: a review. For Ecol Manag 54:257-287

Verbyla D (2011) Browning boreal forests of western North America. Environ Res Lett 6:67-81

Walker XJ, Mack MC, Johnstone JF (2015) Stable carbon isotope analysis reveals widespread drought stress in boreal black spruce forests. Glob Change Biol 21:3102-3113

Wang (2006) Relationship between forest community and climate in northeast China - distribution, structure, diversity and productivity. Peking University
Wang LJ, Niu Z, Kuang D (2010) An analysis of the terrestrial NPP from 2002 to 2006 in China based on MODIS data. Remote Sens Land Resourc 25:113-116

Wang M, Li Y, Ye W, Bornman J, Yan XD (2011) Effects of climate change on maize production, and potential adaptation measures: a case study in Jilin Province, China. Clim Res 46:223-242

Wang G, Mang SL, Riehl B, Huang J, Wang G, Xu L, Huang K, Innes J (2019) Climate change impacts and forest adaptation in the Asia-Pacific region: from regional experts' perspectives. J For Res 30:277-293

Weiskittel AR, Hann DW, Kershaw JA, Vanclay JK (2011) Forest growth and yield modeling. Wiley, New York

Zhang K, Kimball JS, Hogg EH, Zhao M, Oechel WC, Cassano JJ, Running SW (2015) Satellite-based model detection of recent climate-driven changes in northern high-latitude vegetation productivity. J Geophys Res Biogeosci 113:1179-1183

Zhao JF, Yan XD, Jia GS (2008) Simulating the responses of forest net primary productivity and carbon budget to climate change in northeast China. Acta Ecol Sin 28:92-102 (in Chinese with English abstract)

Zhao JF, Yan XD, Jia GS (2009) Changes in carbon budget of northeast China forest ecosystems under future climatic scenario. Chin J Ecol 28:781-787 (in Chinese with English abstract)

Zhao GS, Wang JB, Fan WY, Ying TY (2011) Vegetation net primary productivity in northeast China in 2000-2008: simulation and seasonal change. Chin J Appl Ecol 22:621-630 (in Chinese with English abstract)

Publisher's Note Springer Nature remains neutral with regard to jurisdictional claims in published maps and institutional affiliations. 